\title{
Complex Impedance, Dielectric Properties and Electrical Conduction Mechanism of LaBa0.5Ag0.5FeMnO6 Double Perovskite Oxides
}

Kais Iben Nassar ( $\square$ kaisibnnassar12@gmail.com )

Faculty of Sciences of Sfax: Universite de Sfax Faculte des Sciences de Sfax https://orcid.org/00000002-1917-4399

\section{Nizar Rammeh}

University of Sfax: Universite de Sfax

\section{Sílvia Soreto Teixeira}

University of Aveiro: Universidade de Aveiro

Manuel Pedro F. Graça

University of Aveiro: Universidade de Aveiro

\section{Research Article}

Keywords: Double perovskite oxide, ac conductivity, Complex impedance, Dielectric relaxation, Conduction mechanism

Posted Date: February 26th, 2021

DOl: https://doi.org/10.21203/rs.3.rs-247672/v1

License: (1) This work is licensed under a Creative Commons Attribution 4.0 International License. Read Full License 


\title{
Complex impedance, dielectric properties and electrical conduction mechanism of $\mathrm{LaBa}_{0.5} \mathrm{Ag}_{0.5} \mathrm{FeMnO}_{6}$ double perovskite oxides
}

\author{
K. Iben Nassar ${ }^{*}$, N. Rammeh ${ }^{1}$, Sílvia Soreto Teixeira $^{2}$, M. P. F. Graça ${ }^{2}$ \\ ${ }^{1}$ Laboratoire de physique des matériaux, Faculté des Sciences de Sfax, B.P. 1171, 3000 Sfax, \\ Université de Sfax, Tunisie \\ ${ }^{2}$ I3N-Aveiro, Department of Physics, University of Aveiro, 3810-193, Aveiro, Portugal
}

\begin{abstract}
The double perovskite oxide with formula $\mathrm{LaBa}_{0.5} \mathrm{Ag}_{0.5} \mathrm{FeMnO}_{6}$ was prepared by the sol-gel method. The structural analysis at room temperature indicated that this sample is single phase and crystallize in the cubic system with the Pm-3m space group. The complex impedance spectroscopy has been measured in the range of temperature, 200-340 K, and frequency, $100 \mathrm{~Hz}-1 \mathrm{MHz}$, respectively. Dielectric measurements by analysis of the impedance function, $Z^{\prime \prime}$ as a function of $Z^{\prime}$ versus frequency curves, were mounted to an equivalent circuit consisting of series of combinations of resistor, capacity and constant phase elements. The study of ac conductivity as a function of frequency has been interpreted using the Joncher's law and determines the activation energy. The modulus analysis was also performed indicating the presence of a relaxation process accompanied by a conduction phenomenon.
\end{abstract}

Keywords: Double perovskite oxide; ac conductivity; Complex impedance; Dielectric relaxation; Conduction mechanism

* Correspondent author: kaisibnnassar12@gmail.com 


\section{Introduction}

Magnetism and ferroelectricity are two properties of matter at the origin of important technological applications. Ferroelectric materials can present a residual electrical polarization which can be reversed by the application of an electric field. These properties find many applications such as pyroelectric IR detectors, sensors and non-volatile memories [1]. Indeed, ferromagnetic materials which exhibit remanent magnetization, can be controlled by a magnetic field are widely used for data storage. In addition, single-phase multiferroic materials are relatively few in number because the conditions imposed by the symmetry of their structure are drastic. However, over the past 10 years, with technological advances particularly in the field of thin films - the prospect of using more "agile" materials, of miniaturizing them and making them "multifunctional", has revived the search for multiferroic materials which have the presence of electromagnetic coupling. The number of publications on magnetoelectric coupling and the correlations that exist between magnetic and dielectric properties has increased considerably in recent years.

There are several materials that belongs to the family of double perovskites $\mathrm{La} \mathrm{A} \square \mathrm{B} \square \mathrm{B} \square \square \mathrm{O}_{6}$ with a rare-earth elements $\mathrm{A} \square \square \square \square \mathrm{a}, \mathrm{Ca}, \mathrm{Pb}, \mathrm{Ag}$ ) and transition metals $\mathrm{B} \mathrm{B}_{\mathrm{B}} \mathrm{B}$ ray diffraction and electrical impedance spectroscopy and crystallizes, at room temperature, in the cubic systems [2]. On the other hand, the $\mathrm{La}_{1-\mathrm{x}} \mathrm{Ba}_{\mathrm{x}} \mathrm{MnO}_{3}$ compounds have a lot of interest due to the understanding of the fundamentals of physics being strongly correlated with electronic systems and their potential in technological applications $[3,4,5,6]$. Although the $\mathrm{LaMnO}_{3}$ is an antiferromagnetic and an insulator material, upon alkaline earth doping (site A ion), it becomes both ferromagnetic and metal with high magnetoresistance property [7]. In a recent work, Mansuri and Varsheny [8] show that the $\mathrm{La}_{1-\mathrm{x}} \mathrm{Ba}_{\mathrm{x}} \mathrm{MnO}_{3}$ crystallizes in cubic or hexagonal systems. Moreover, Bebenina and other researchers confirm that doping this compound leads to a decrease of the critical temperature and leads to structure changes [9]. Also, for certain doping values in site A, these materials become both metals and ferromagnetics, at low temperature, while the conductivity exhibits a semiconductor behavior at high temperature $[10,11]$. The researchers have extensively studied this system and made a substitution at site A.

In this study, it is focused on the synthesis of $\mathrm{LaBa}_{0.5} \mathrm{Ag}_{0.5} \mathrm{FeMnO}_{6}$ (LBAFMO) and structural, electrical and dielectric characterization of double perovskite material as a preliminary study of new material development. Thus, the aim of this study was to synthesize 
at multiferroic material and to study their physical properties in order to understand the characteristics of the crystal structure and the dielectric properties at different frequencies and temperatures.

\section{Materials and methods}

The synthesis of $\mathrm{LaBa}_{0.5} \mathrm{Ag}_{0.5} \mathrm{FeMnO}_{6}$ compound was carried out by using the sol-gel method, using oxide materials, namely $\mathrm{La}_{2} \mathrm{O}_{3}, \mathrm{BaCO}_{3}, \mathrm{Ag}, \mathrm{Fe}_{2} \mathrm{O}_{3}$ and $\mathrm{MnO}_{2}$. Precursors were mixed together in a solution of nitric acid and distilled water and adding citric acid and ethylene glycol to homogenize the reaction medium. The solution was heated at $80{ }^{\circ} \mathrm{C}$ for $4 \mathrm{~h}$, and then the powder obtained was calcined at $500{ }^{\circ} \mathrm{C}$ for $6 \mathrm{~h}$. Finally, powder was ground in a mortar and heat-treated respectively at $800^{\circ} \mathrm{C}, 1000^{\circ} \mathrm{C}$ for $12 \mathrm{~h}$.

The structure, phase purity and homogeneity of the prepared sample was identified by X-ray powder diffraction (XRD) (PHILIPS diffractometer, X'PERT PRO MPD) spectrum registered at room temperature in a range of Bragg angle between $2 \theta=20^{\circ}$ and $80^{\circ}$ using an anticathode copper radiation $\left(\lambda_{\mathrm{CuK} \alpha}=1.54060 \AA\right)$ with a step size of $\Delta \theta=0.02^{\circ}$. The X-ray pattern was analyzed with Fullprof program [12]. The dielectric measurements were carried out using a precision impedance analyzer, Agilent 4294A, in the Cp-Rp configuration, in a frequency range of $100 \mathrm{~Hz}-1 \mathrm{MHz}$ and temperatures from 200 to $340 \mathrm{~K}$, using a bath-cryostat. The samples are in a helium atmosphere to improve the heat transfer and avoid moisture. The samples were used in the disk form used (diameter $=11 \mathrm{~mm}$; thickness $=1.68 \mathrm{~mm}$ ), with the opposite surfaces painted with conductive silver paste, to the electrodes.

\section{Results and discussion}

\subsection{Structural analysis}

Figure 1 shows the X-ray diffraction pattern of LBAFMO at room temperature. From the X-ray diffractogram, is noticed an accordance between the intensities of the measured and calculated lines of diffraction, which indicates a good crystallization of material. In addition, all reflection-peaks are indexed in the cubic system with space group Pm-3m. Rietveld refinements were performed in the XRD diffractograms to estimate the lattice parameters being $\mathrm{a}=\mathrm{b}=\mathrm{c}=3.8955 \AA$ with a volume $\mathrm{V}$, of $59.1139 \AA^{3}$. The reliability factors were found, it was obtained a goodness factor of $\square^{2}=1.56, \mathrm{R}_{\mathrm{F}}=1.76$ and Bragg factor $\mathrm{R}_{\mathrm{B}}=1.89$. In the context of the morphological study of grains, a method has been proposed by Laue 
SCHERRER [13] consists of determining the size of crystallites by referring to the X-ray diffractogram.

$$
\mathrm{D}=\frac{\mathrm{K} \cdot \lambda}{\beta \cdot \operatorname{COS} \theta}
$$

Where $D$ is average size of crystallites, $K=0.89, \lambda$ is wavelength ( $1.54060 \AA), \beta$ is width at mid-height of the peak and $\theta$ is the diffraction angle of the peak considered. We get the grain size is $470 \mathrm{~nm}$. Scanning electron microscopy was performed to study the sample morphology. The purpose of the morphological study is to observe the crystallinity state of the sintered powder and to see the growth of the grains. Figure 2 presents the FESEM images of the sample. The morphology is dense and uniform and the grain equal to $467 \mathrm{~nm}$, which is in agreement with the particle size, calculated from the XRD results.

\subsection{Impedance analysis}

Impedance spectroscopy consists of measuring the response of the system in study, following an alternating sinusoidal electric field with low amplitude $(\mathrm{V}=0.5 \mathrm{~V})$. In literature, the electrical conduction in oxide materials is mainly due to the hopping from the ions, like $\mathrm{Mn}^{3+}, \mathrm{Mn}^{4+}$ and $\mathrm{Fe}^{3+}$ or the overlapping of $\mathrm{d}$ orbital of cations [14]. By applying an electric field, electrons will migrate from one site to another and give an electrical response.

The dependence of the complex impedance of sample $\mathrm{LaBa}_{0.5} \mathrm{Ag}_{0.5} \mathrm{FeMnO}_{6}$ with the temperatures is shown in Figure 3. The obtained spectra are formed by a single semi-circular arc which indicates the grain behavior. In addition, with the temperature increase, the radius of semicircles corresponding to the resistance decreases and their center is located under the real axis, which causes a thermally activated conduction mechanism and non-Debye model [15]. To study the properties of LBAFMO, was modelled the complex impedance spectra using a Zview software. The best fit is obtained using an equivalent circuit which can be described as a parallel combination of capacitance (C1), constant phase elements (CPE1) and resistance (R1) as shown in Fig. 3. The parameters of the equivalent circuit are summarized in Table. The constant phase element $\left(\mathrm{Z}_{\mathrm{CPE}}\right)$ is determined from the following equation [16]:

$$
\mathrm{Z}_{\mathrm{CPE}}=\frac{1}{\mathrm{Q}(\mathrm{jw})^{\alpha}}
$$

It is determined the resistance $\mathrm{R}, \mathrm{Q}$ and $\alpha$ in order to reduce the difference between the calculating and experimental data. With $\mathrm{Q}$ denotes the value of the pseudo-capacity of the 
CPE element while $\alpha$ indicates the capacitive nature of the material. If $\alpha=0$, it behaves like an Ohmic resistance and if $\alpha=1$, it becomes an ideal capacitor.

The real $Z^{\prime}$ and imaginary (-Z") parts of the complex impedance were calculated respectively, according to the following formulas:

$$
\begin{aligned}
& Z^{\prime}=\frac{R^{-1}+Q \omega^{\alpha} \cos \left(\frac{\alpha \pi}{2}\right)}{\left(R^{-1}+Q \omega^{\alpha} \operatorname{Cos}\left(\frac{\alpha \pi}{2}\right)^{2}+\left(C \omega+Q \omega^{\alpha} \sin \left(\frac{\alpha \pi}{2}\right)^{2}\right)\right)} \\
& -Z^{\prime \prime}=\frac{R^{-1}+Q \omega^{\alpha} \sin \left(\frac{\alpha \pi}{2}\right)}{\left(R^{-1}+Q \omega^{\alpha} \operatorname{Cos}\left(\frac{\alpha \pi}{2}\right)^{2}+\left(C \omega+Q \omega^{\alpha} \sin \left(\frac{\alpha \pi}{2}\right)^{2}\right)\right)}
\end{aligned}
$$

The variation of the real part of the impedance $Z^{\prime}$ as a function of the frequency at different temperatures is shown in Fig. 4. In the region of low frequencies, at low temperatures, the impedance value is higher and then it gradually decreases with increasing frequency. For certain frequency $\left(>10^{5} \mathrm{~Hz}\right.$ ), $\mathrm{Z}^{\prime}$ is almost constant, then it decreases. Moreover, values of $\mathrm{Z}^{\prime}$ converge at high frequencies towards a minimal value. This result can be explained by releases of the space charge polarization, reducing the reduction of the material potential barrier [17]. In Fig. 5 it is represented the imaginary part of the complex impedance Z" as a function of the frequency, at different temperatures. By analysing the Figure 5, it is visible the appearance of peaks, in which the correspondent frequency of the Z" maximum, is shifted to higher frequencies with the increases of temperature. The displacement of this maximum confirms the existence of dielectric process, characteristic of the material. This relaxation can be explained by the accumulation of charges on the grain boundaries which polarize under the effect of an electric field [18].

\subsection{Dielectric studies}

The complex permittivity of non-Debye model for a dielectric material is given by the following relation [19].

$$
\varepsilon^{*}(\mathrm{w})=\varepsilon_{\infty}+\frac{\left(\varepsilon_{S}-\varepsilon_{\infty}\right)}{(1+\mathrm{j} \omega \tau)^{1-\alpha}}+\frac{\sigma_{\mathrm{dc}}}{\mathrm{j} \omega \varepsilon_{0}}
$$

Where $\varepsilon_{\infty}$ is the high frequency permittivity, $\varepsilon_{S}$ is the static permittivity, $\varepsilon_{0}$ is the permittivity of free space, $\tau$ is the dielectric relaxation time, $\omega$ is the angular frequency, $\alpha$ is a parameter between 0 and 1, former value giving the result caracteristic of a Debye relaxation and $\sigma_{\mathrm{dc}}$ represents the ohmic conductivity [20,21,22]. Figure 6(a) shows the variation of the real part $\varepsilon^{\prime}$ of the complex permittivity with the frequency, which increases with the temperature, but it 
decreases with increasing frequency which explained by the dielectric polarization mechanism of the material. In fact, at low frequencies, the values of the $\varepsilon^{\prime}$ are very high being that fact attributed the accumulation of charge carriers between the sample and the electrodes such as the interfacial polarization [23, 24]. Moreover, concerning to Figure 6(b) the variation of the imaginary part $\varepsilon^{\prime \prime}$ of complex permittivity as a function of frequency at different temperatures, it is visible a decrease of the $\varepsilon^{\prime \prime}$ with the frequency increase which can be attributed due to the presence of a relaxation time distribution and to the contribution of charge carrier density $[25,26]$.

\subsection{Electrical modulus studies}

The electrical modulus was used to study the conduction mechanism and relaxation phenomenon behavior in the material [27]. It can be determined from the following mathematical formalism [28]:

$$
M^{*}=M^{\prime}+i M^{\prime \prime}=i \omega C_{0} Z^{*}=\frac{1}{\varepsilon^{*}}
$$

The real $\left(\mathrm{M}^{\prime}\right)$ and imaginary $\left(\mathrm{M}^{\prime \prime}\right)$ parts of the complex modulus were obtained from the complex impedance data $\left(Z^{*}(\omega)=Z^{\prime}-\mathrm{i} Z^{\prime \prime}\right)$ by the relations:

$$
\begin{aligned}
& M^{\prime}=\omega C_{0} Z^{\prime} \\
& M^{\prime \prime}=\omega C_{0} Z
\end{aligned}
$$

where $\mathrm{C}_{0}$ is the vacuum capacitance of the cell.

Figure 7 (a) shows the variation of the real part of the electrical modulus at different temperatures as a function of frequency. It is noticed that the values of $\mathrm{M}^{\prime}$ are very low, at low frequency, but they attain a maximums at high frequency for all temperatures. In addition, if $\varepsilon^{\prime}$ decreases, $M^{\prime}$ increases, we have said that in the preceding, the permittivity values are important, that explained by the accumulation of electric charges at the interface between the electrode and material. This result confirms the dielectric characterizations. The dependence of the modulus imaginary part $\mathrm{M}^{\prime \prime}$ as a function of frequency (Figure 7 (b)) are visible a relaxation processes. $\mathrm{M}$ " is initially low, increases with frequency at some temperature until reaching a maximum which presents a peak of relaxation. If the temperature increases, the modulus values are shifted to the maximum at a higher frequency. The relaxation peaks show that the sample is ionic conductor. The imaginary part of modulus is maximal at $\omega \tau=1$. 
The activation energy of the relaxation processes can be calculated through the expression [29].

$$
\mathrm{F}_{\mathrm{P}}=\mathrm{f}_{0} \exp \left(-\mathrm{E}_{\mathrm{a}} / \mathrm{K}_{\mathrm{B}} \mathrm{T}\right)
$$

Where $f_{0}$ the frequency at high temperature is, $K_{B}$ is the Boltzmann constant, $E_{a}$ is the activation energy and $\mathrm{T}$ is the temperature. By plotting the relaxation frequency $\mathrm{F}_{\mathrm{p}}$, as a function of the temperature inverse 1000/ T (Figure 8) it is obtained a linear dependence, obeying to an Arrhenius behaviour [30]. The reached activation energy is $0.386 \mathrm{eV}$.

\subsection{Electrical conductivity studies}

Conductivity measurements are important for all dielectric material, as they give a lot of information about the conduction mechanism. Figure 9 represents the frequency dependence of the ac conductivity at different temperatures. In addition, the variation of the conductivity shows two zones at low and high frequency. At low frequencies, the conductivity has a large plateau which corresponds to direct current (dc) conductivity. However, at high frequency, it gradually increases with increasing frequency.

Furthermore, the conductivity curves can be described by the Jonscher relation as [31]:

$$
\sigma(\omega)=\sigma_{\mathrm{dc}}+\mathrm{A} \omega^{\mathrm{s}}
$$

Where $\sigma_{\mathrm{dc}}$ the dc-conductivity, $\omega$ is the pulsation, $\mathrm{A}$ is a constant which depends on the temperature and $\mathrm{s}(0 \leq \mathrm{s} \leq 1)$ is a dimension less parameter which characterizes the dispersion in the material [32]. As illustrated in Fig. 10 the dependence of the conductivity with the temperature inverse follows the Arrhenius law, [32]:

$$
\sigma_{\mathrm{dc}} \mathrm{T}=\sigma_{0} \exp \left(\frac{-\mathrm{E}_{\mathrm{a}}}{\mathrm{K}_{\mathrm{B}} \mathrm{T}}\right)
$$


Where $E_{a}$ is the activation energy, $\square$ is the pre-exponential term and $k_{B}$ is the Boltzmann's 
constant. The obtained activation energy value of $\mathrm{LaBa}_{0.5} \mathrm{Ag}_{0.5} \mathrm{FeMnO}_{6}$ is $0.392 \mathrm{eV}$, which may differ from the value obtained from the modulus analysis, which shows that the charge transport properties originate from cause of type of ac conduction mechanism. The temperature dependence of the exponent $S$ is studied to determine the conduction model $[33,34]$, in the material. The obtained values of $S$ are in the range of 0.993 to 0.664 , depending on temperature (Fig.11). The tendency of $\mathrm{S}$ is not constant, first decreases and then increases with temperature, according to the Overlapping Conduction Model (OLPT) [35].

\section{Conclusion}

It was synthesized the compound $\mathrm{LaBa}_{0.5} \mathrm{Ag}_{0.5} \mathrm{FeMnO}_{6}$ by the sol-gel method. The structural study indicates that the sample is a single phase. The dielectric measurements of this compound are studied in the frequency and temperature ranges of $100 \mathrm{~Hz}-1 \mathrm{MHz}$ and $200-340 \mathrm{~K}$ respectively. In addition, the $\mathrm{Z}^{\prime}$ and $\mathrm{Z}^{\prime \prime}$ curves merge above $10^{5} \mathrm{~Hz}$ for different temperatures, indicate the presence of a relaxation phenomenon in our material and the modulus analysis also shows a relaxation peak. Moreover, the variation of AC conductivity is obeying the Jonscher's law. The activation energies found from conductivity and modulus analysis are very close, confirm that the charge transport between ions occurs by a jump mechanism which is the OLPT conduction model. 


\section{References:}

[1] Y.Yokomizo, T. Takahashi and S. Noumira, J. Phys. Soc. Japan, 28, 1278-84 (1970).

[2] A. BenHafsia, N. Rammeh, M.Farid, M.Khitouni, Ceramics International, 42, (2016), 3673 .

[3] Y. Tokura, Y. Tomioka J. Magn. Magn. Mater, 200 (1999), pp. 1 - 23.

[4] HL Ju, C. Kwon, Qi Li, RH Greene, T. Venkatesan Appl. Phys. Lett. , 65 (1994), p. $2108-2110$.

[5] B. Raveau, M. Hervieu, A. Maignan, C. Martin J. Mater. Chem. 11 (2001), pp. 29 - 36.

[6] R. Von Helmolt, J. Wecker, B. Holzapfel, L. Schultz, K. Samwer Phys. Rev. Lett, 71 (1994), pp. $2331-2333$.

[7]R. Mahendiran, SK Tiwary, AK Raychaudhuri, TV Ramakrishanan, R. Mahesh, N. Ran gavittal , CNR Rao Phys. Rev. B , 53 ( 1996 ) , pp. 3348 - 3358.

[8] I. Mansuri, D. Varsheny, J. Alloy. Compd. 513 (2012) 256-265.

[9] R. I. Zainullinaa, N.G. Bebenina, V.V. Ustinova, Ya. M. Mukovskiib, J. Alloy. Compd. 467 (2009) 22-26.

[10] G. Husnain, F. Tao, S.D. Yao, B 405, 2340 (2010).

[11] C.W. Zhang, P.J. Wang, P. Li, Solid State Sci. 13, 480-483 (2011).

[12] J. Rodriguez-Carvajal, A program for Rietveld refinement and pattern matching analysis, Meeting on powder diffraction, Toulouse, France, 1990.

[13] F.Ramez anipour, B. Cowie, S. Derakhshan, J.E.Greedan ,L. M.D.Cranswick Journal of Solid State Chemistry 182153 (2009).

[14] Elbadraoui, E.; Baudour, J. L.; Bouree, F.; Gillot, B.; Fritsch, S.; Rousset, A. Cation. Solid State Ionics 1997, 93, 219-225.

[15] H. Nefzi, F. Sediri, H. Hamzaoui, N. Gharbi, Mater. Res. Bull. 48 (2013) 1978.

[16] Y. Olofsson, J. Groot, T. Katrašnik, e G. Tavcar, in Electric Vehicle Conference (IEVC), 2014 IEEE International, pp. 1-6, 2014. 
[17] M. Ganguli, M. Harish Bhat., K. J. Rao, Phys.Chem.Glas.40 (1999) 297.

[18] F. Alvarez, A. Alegría, J. Phys. Rev. B 47 (1993) 125.

[19] K.S. Cole, R.H. Cole, J. Chem. Phys. 10 (1942) 98-105.

[20] K.S. Cole, R.H. Cole, J .Chem. Phys. 9 (1941) 341.

[21] MPF Graça, MGF da Silva, ASB Sombra, MA Valente, Journal of non-crystalline solids 353 (47-51), 4390-4394.

[22] MGF da Silva, ASB Sombra, MA Valente, Journal of non-crystalline solids 352 (42-49), 5199-5204.

[23] K. S. Cole, P. M. Krishna, D. M. Prasad, J.H. Lee, J.S. Kim, J. Alloy. Compd. 464 (2008) 497.

[24] M. P. F Graça, P. R Prezas, M. M Costa, M. A Valente, Journal of sol-gel science and technology 64 (1), 78-85.

[25] H. Kolodziej, L.Sobczyk, Acta Phys. Pol. A 39 (1971) 59.

[26] X. Qian, N. Gu, Z. Cheng, X. Yang, E.wang, S. Dong, Electrochim. Acta 46 (2001) 1829.

[27] F.S. Howell, R.A. Bose, P.B. Macedo, C.T. Moynihan, Phys. Chem. Glassses 13 (1972) 171.

[28] S. Ghosh, A. Ghosh, Solid State Ion.149 (2002) 67.

[29] M. D. Migahed, N. A. Bakr, M. I. Abdel-Hamid, O. EL- Hannafy, M. El- Nimr, J. Appl. Polym. Sci. 59(1996) 655-662.

[30] Atkins P., de Paua J. Physical Chemistry for the Life Sciences. pg 256-259. New York. Oxford Univeristy Press. 2006.

[31] A.K. Jonscher, Universal Relaxation Law, Chelsea Dielectics Press, London, 1996.

[32] M. D. Ingram, Phys. Chem. Glasses 28 (1987) 215.

[33] S. R, Philos. Mag. B 36 (1977) 1291.

[34] G.E, Phys. Rev. B: Condens. Matter 6 (1972) 1572.

[35] Tabip, A., Sdiri, N., Elhouichet, H., Ferid, M.: J. Alloys Compd. 622, 687-694 (2015). 


\section{Figures Captions}

Fig. 1: X-ray powder diffraction of $\mathrm{LaBa}_{0.5} \mathrm{Ag}_{0.5} \mathrm{FeMnO}_{6}$ recorded with the $\mathrm{Cu} \mathrm{K}_{\alpha}$ radiation. Fig. 2 : FESEM images of $\mathrm{LaBa}_{0.5} \mathrm{Ag}_{0.5} \mathrm{FeMnO}_{6}$ nanoparticles.

Fig. 3 : Complex impedance spectrum at different temperatures with electrical equivalent circuit.

Fig. 4: Variation of real part of the impedance as a function of frequency at various temperatures.

Fig. 5 : Variation of imaginary part of the impedance as a function of frequency at various temperatures.

Fig. 6 (a) : Variation of real part of the permittivity as a function of frequency at various temperatures.

Fig. 6 (b) : Variation of imaginary part of the permittivity as a function of frequency at various temperatures.

Fig. 7 (a) : Variation of $\mathrm{M}^{\prime}$ as a function of frequency at various temperatures.

Fig. 7 (b) : Variation of $\mathrm{M}^{\prime \prime}$ as a function of frequency at various temperatures.

Fig. 8 : Variation of $F_{p}$ frequency relaxation at temperature.

Fig. 9 : Frequency dependence of the AC conductivity at various temperatures.

Fig. 10 : Variation of $\operatorname{Ln}\left(\sigma_{\mathrm{dc}} \times \mathrm{T}\right)$ as a function of $1000 / \mathrm{T}$.

Fig. 11 : Variation of the universal exponent $\mathrm{S}$ as a function of temperature.

\section{Table captions}

Table : The parameters for the circuit equivalent of $\mathrm{LaBa}_{0.5} \mathrm{Ag}_{0.5} \mathrm{FeMnO}_{6}$. 
Figures

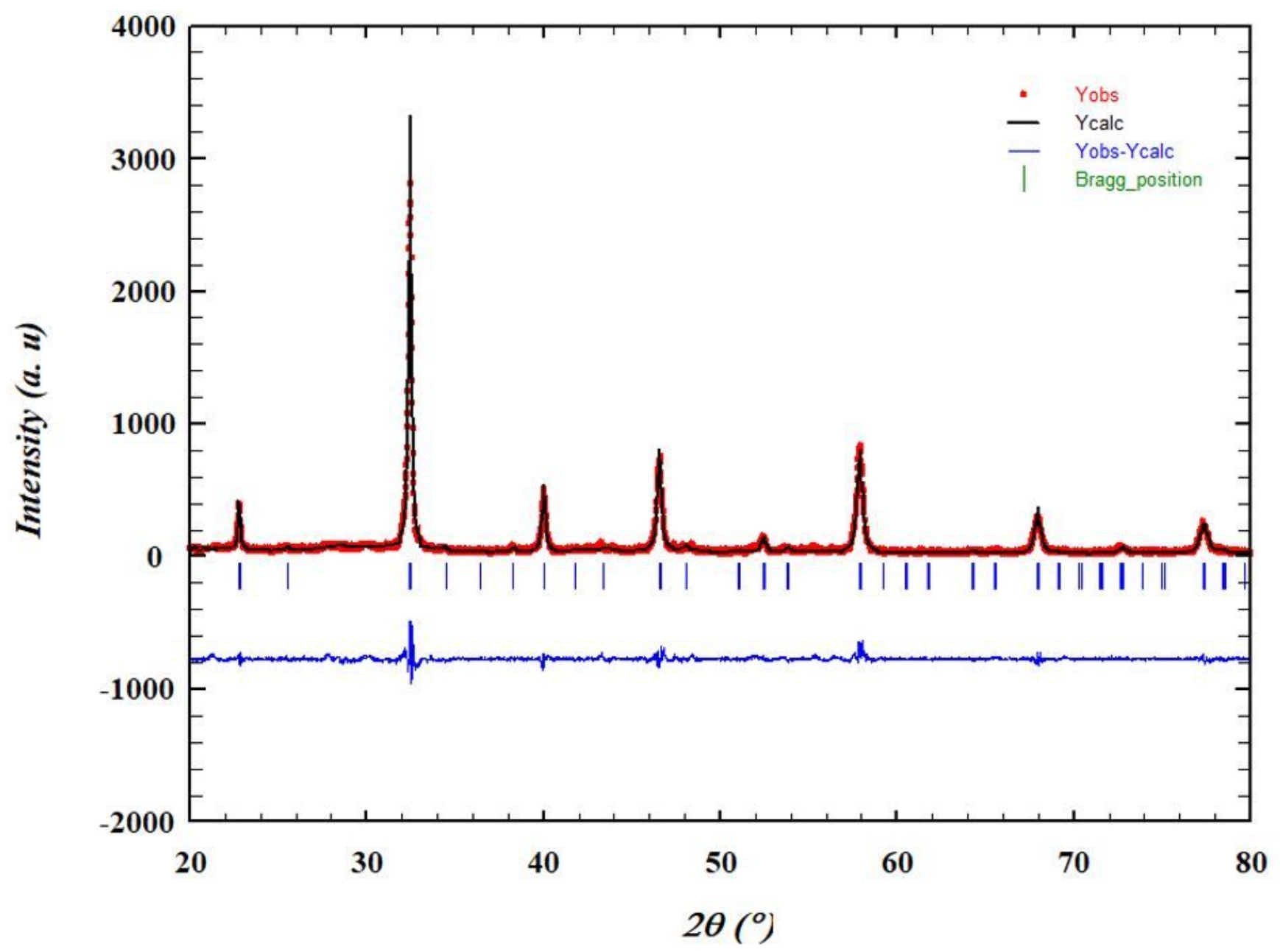

Figure 1

X-ray powder diffraction of $\mathrm{LaBa} 0.5 \mathrm{Ag} 0.5 \mathrm{FeMnO6}$ recorded with the $\mathrm{Cu}$ Ka radiation.
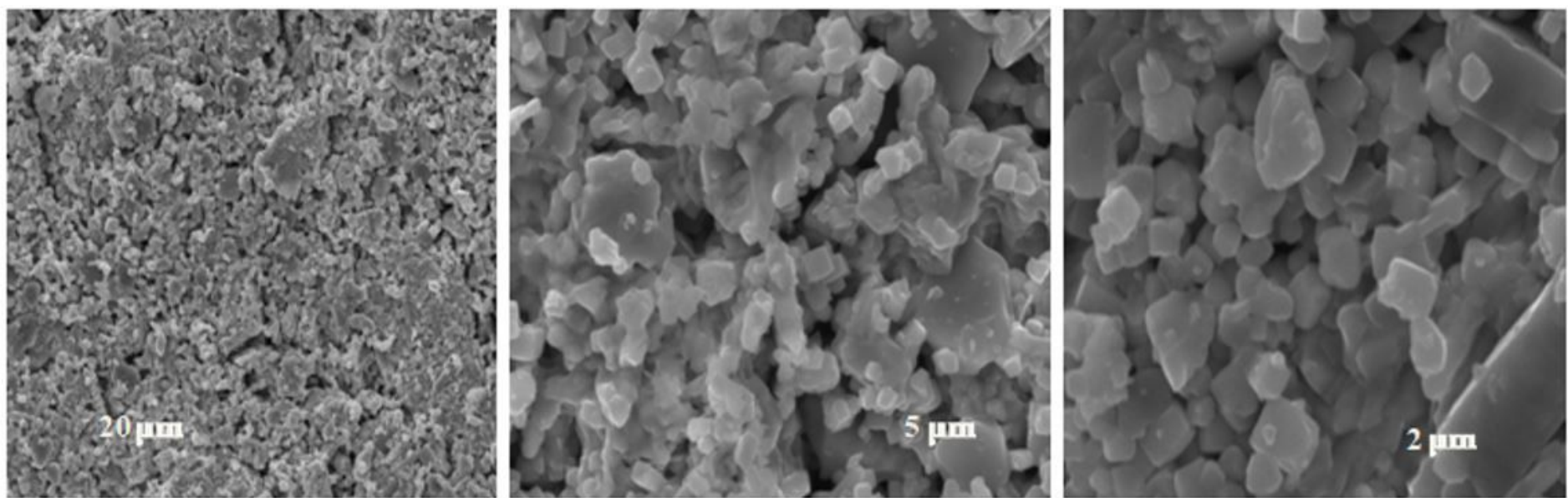
Figure 2

FESEM images of LaBa0.5Ag0.5FeMnO6 nanoparticles.

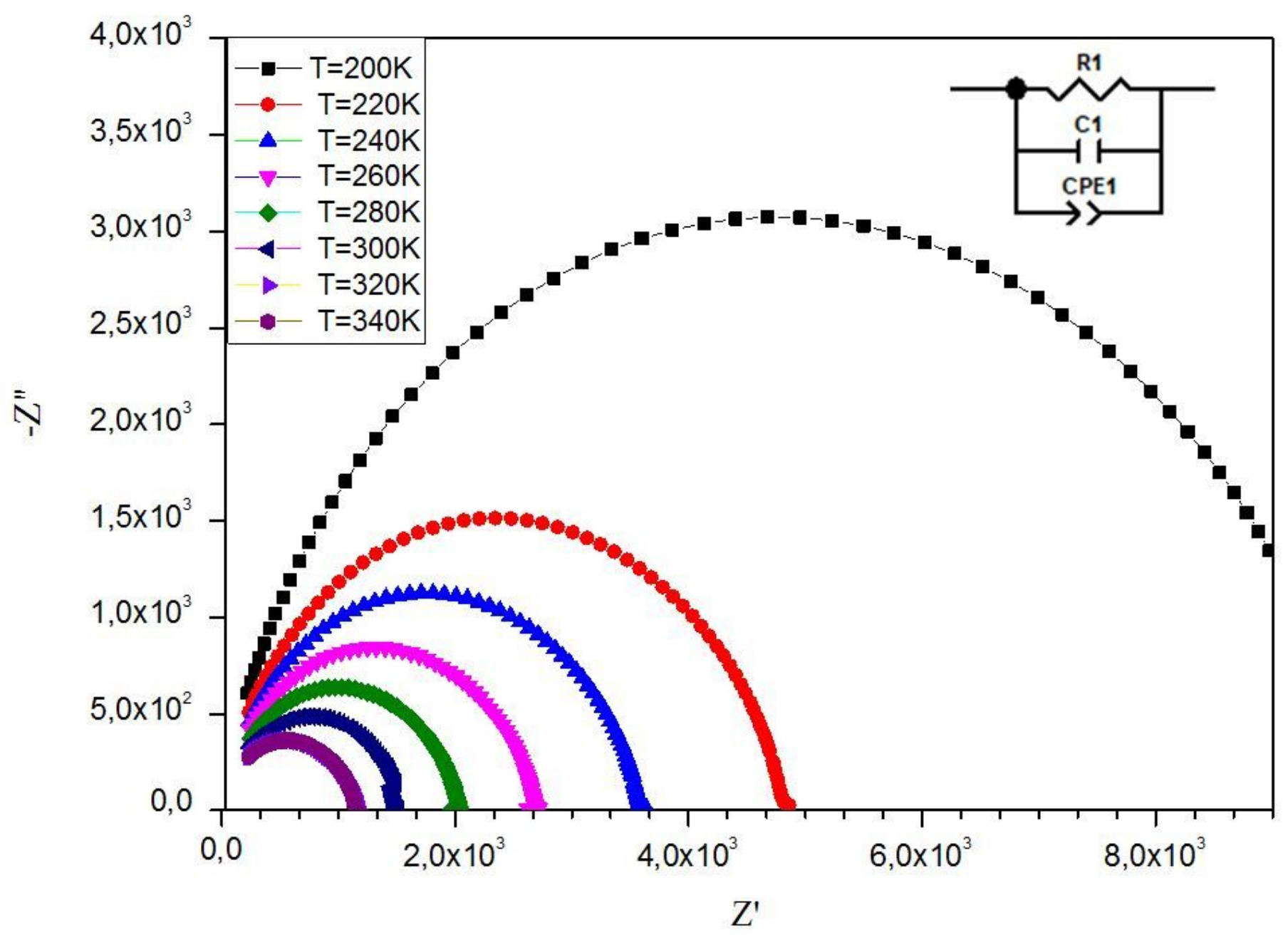

Figure 3

Complex impedance spectrum at different temperatures with electrical equivalent circuit. 


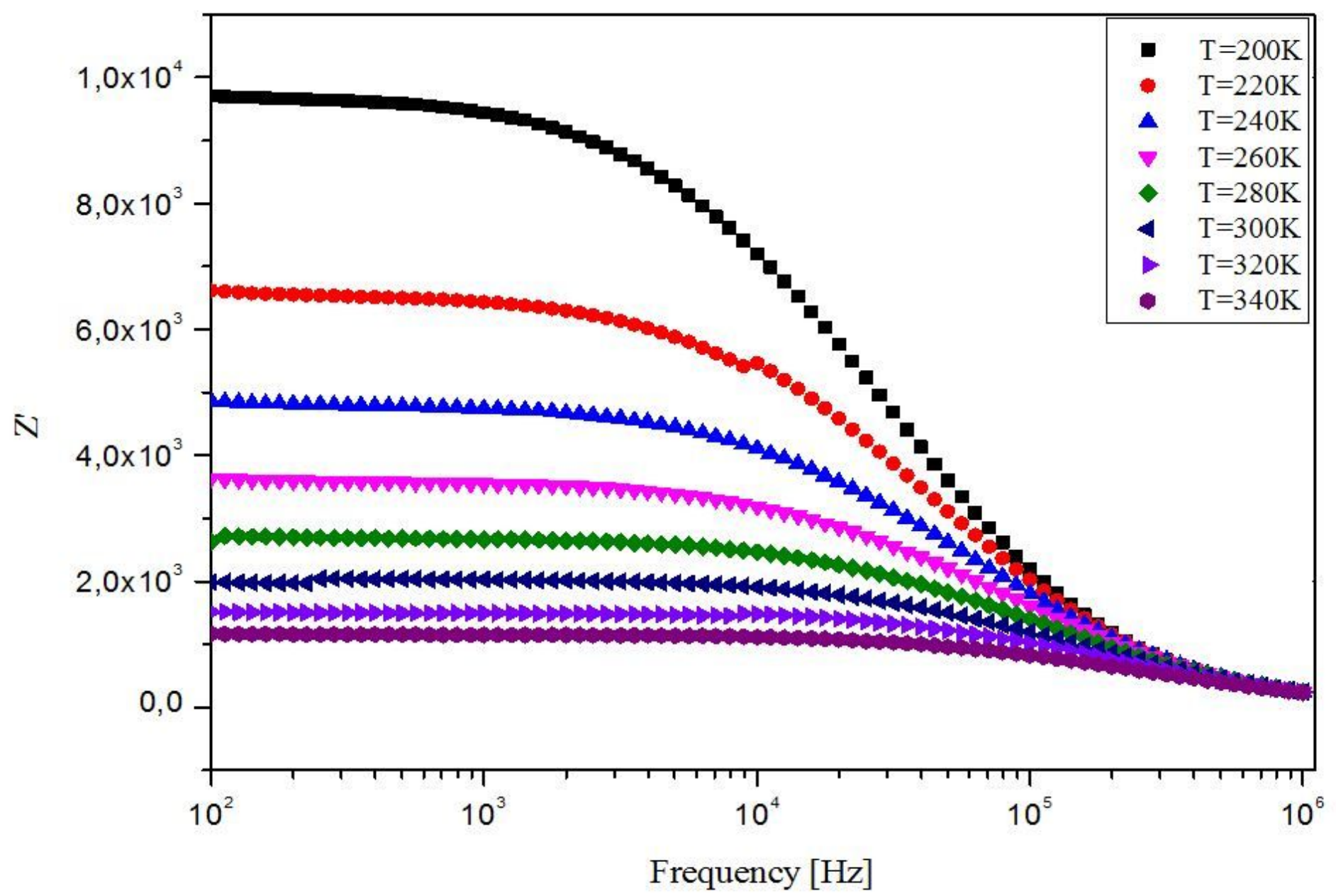

Figure 4

Variation of real part of the impedance as a function of frequency at various temperatures. 


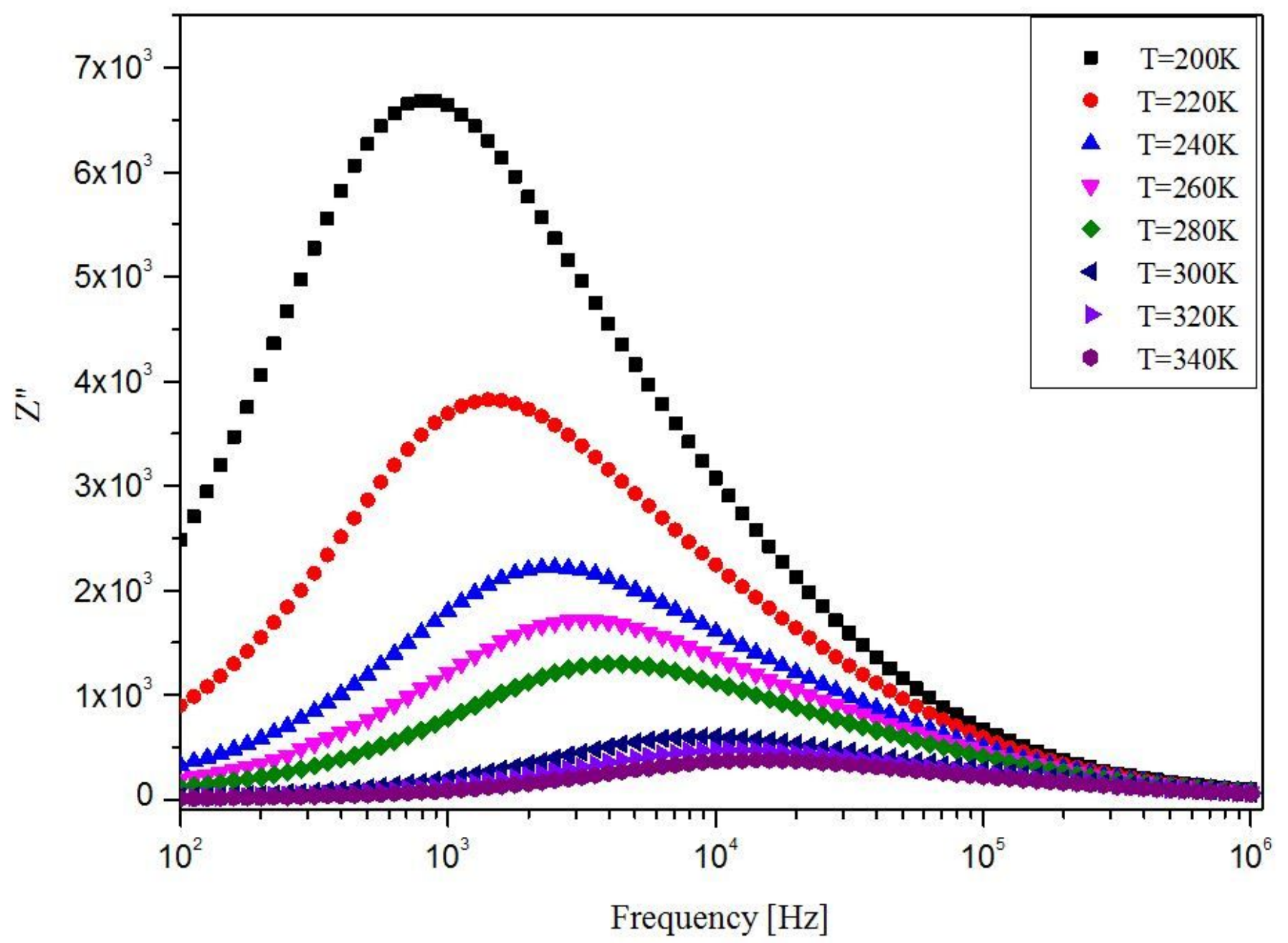

Figure 5

Variation of imaginary part of the impedance as a function of frequency at various temperatures. 

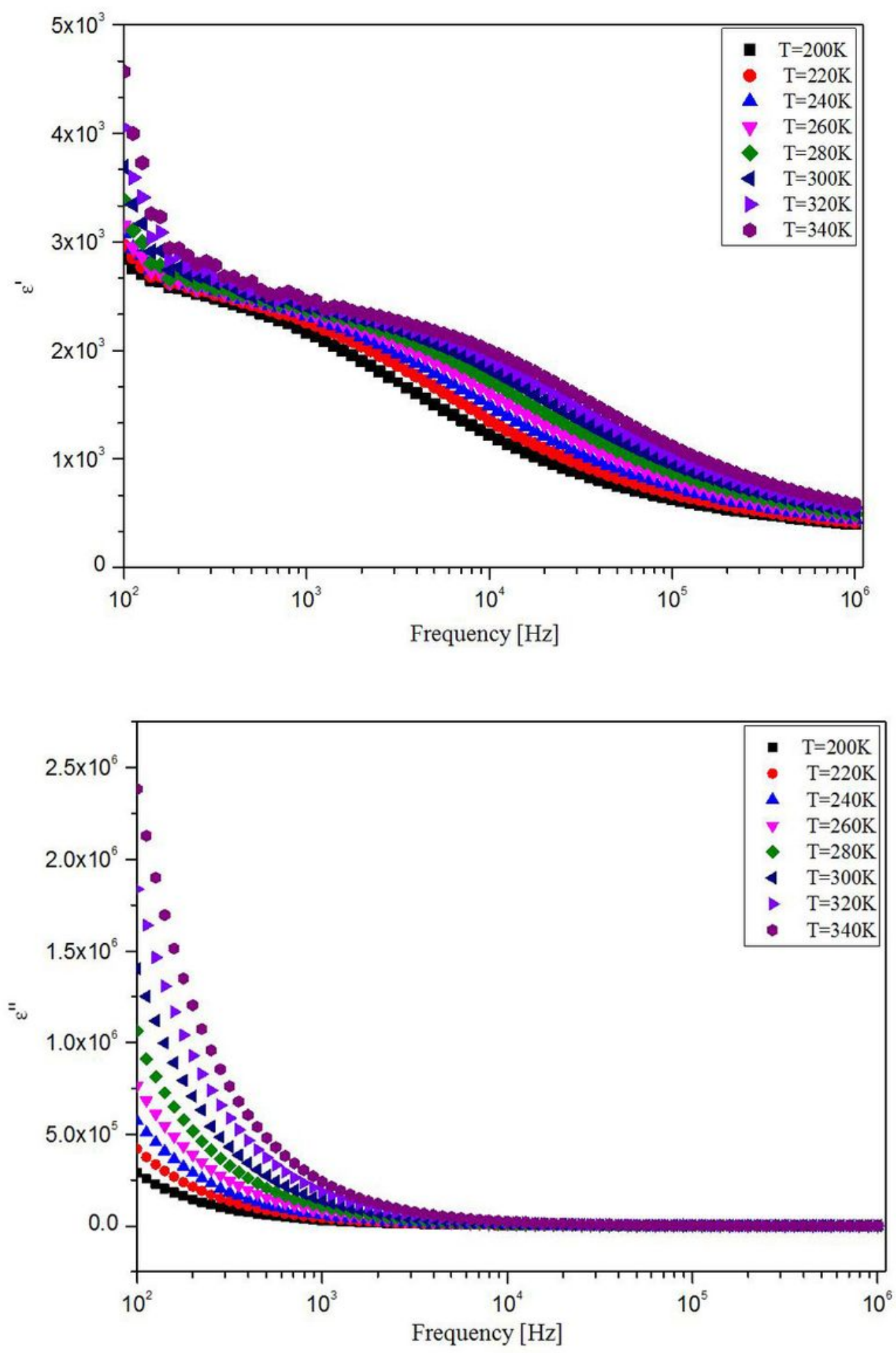

Figure 6

(a) : Variation of real part of the permittivity as a function of frequency at various temperatures. (b) : Variation of imaginary part of the permittivity as a function of frequency at various temperatures. 

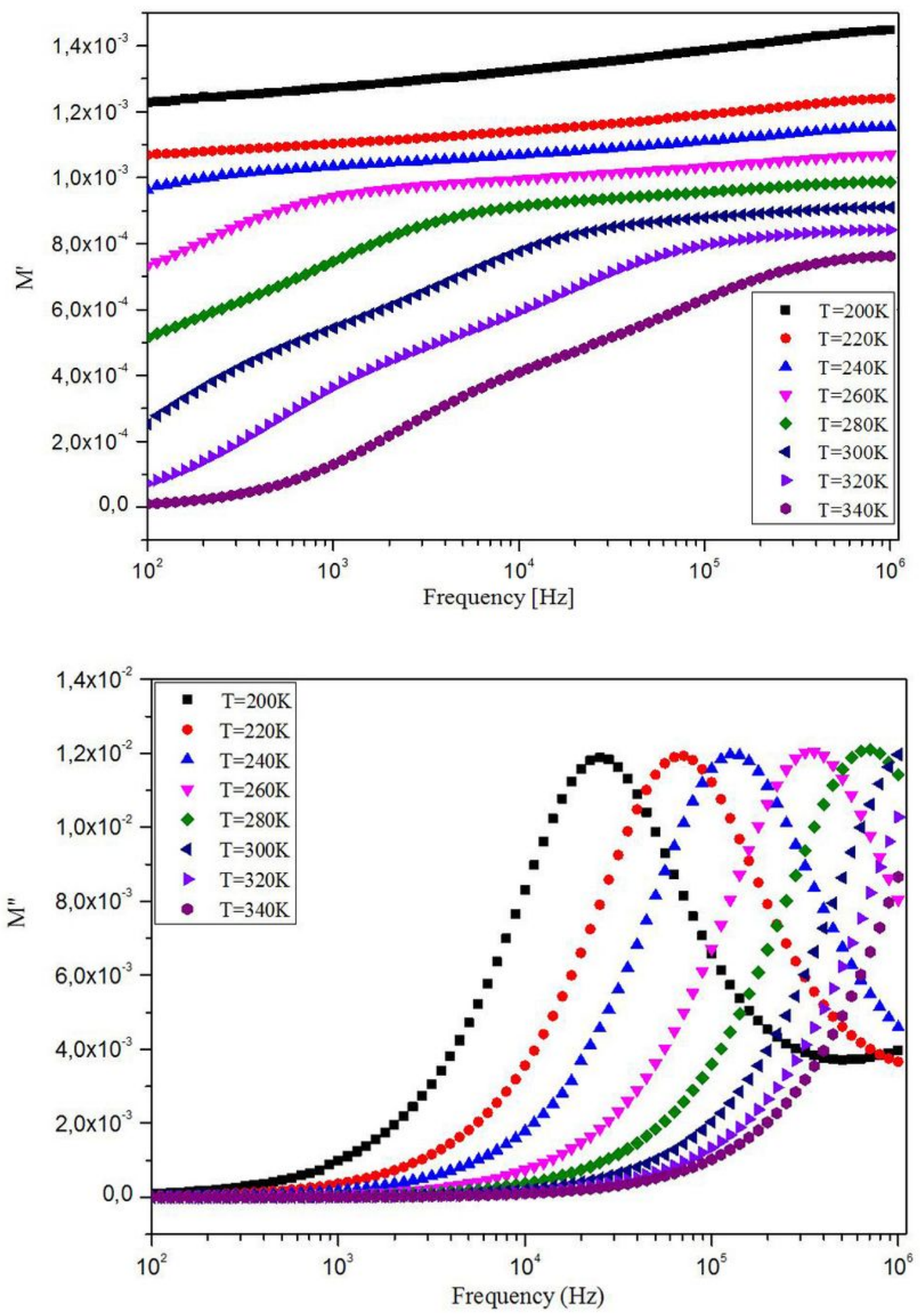

Figure 7

(a) : Variation of $\mathrm{M}^{\prime}$ as a function of frequency at various temperatures. (b) : Variation of $\mathrm{M}^{\prime \prime}$ as a function of frequency at various temperatures. 


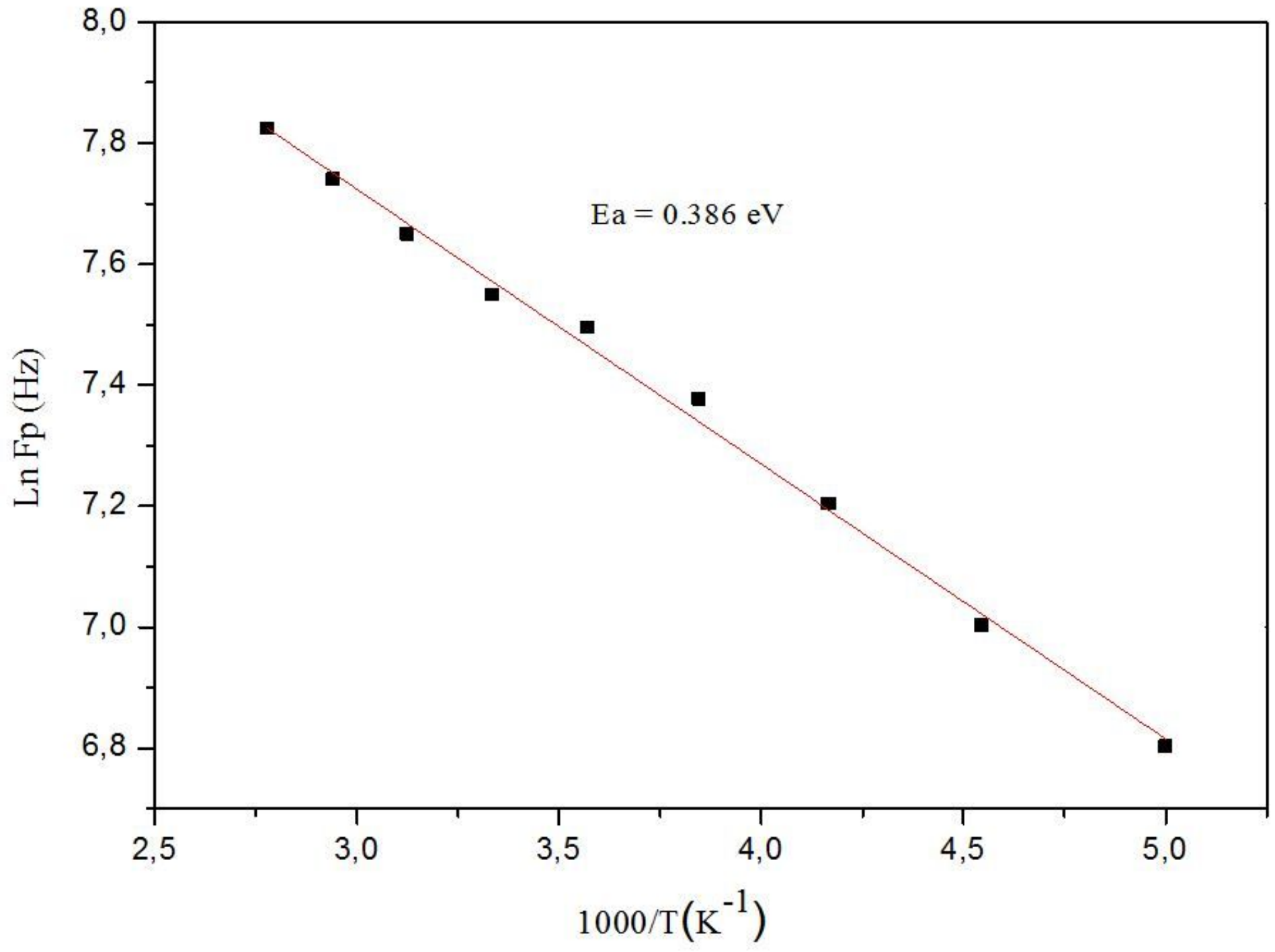

Figure 8

Variation of Fp frequency relaxation at temperature. 


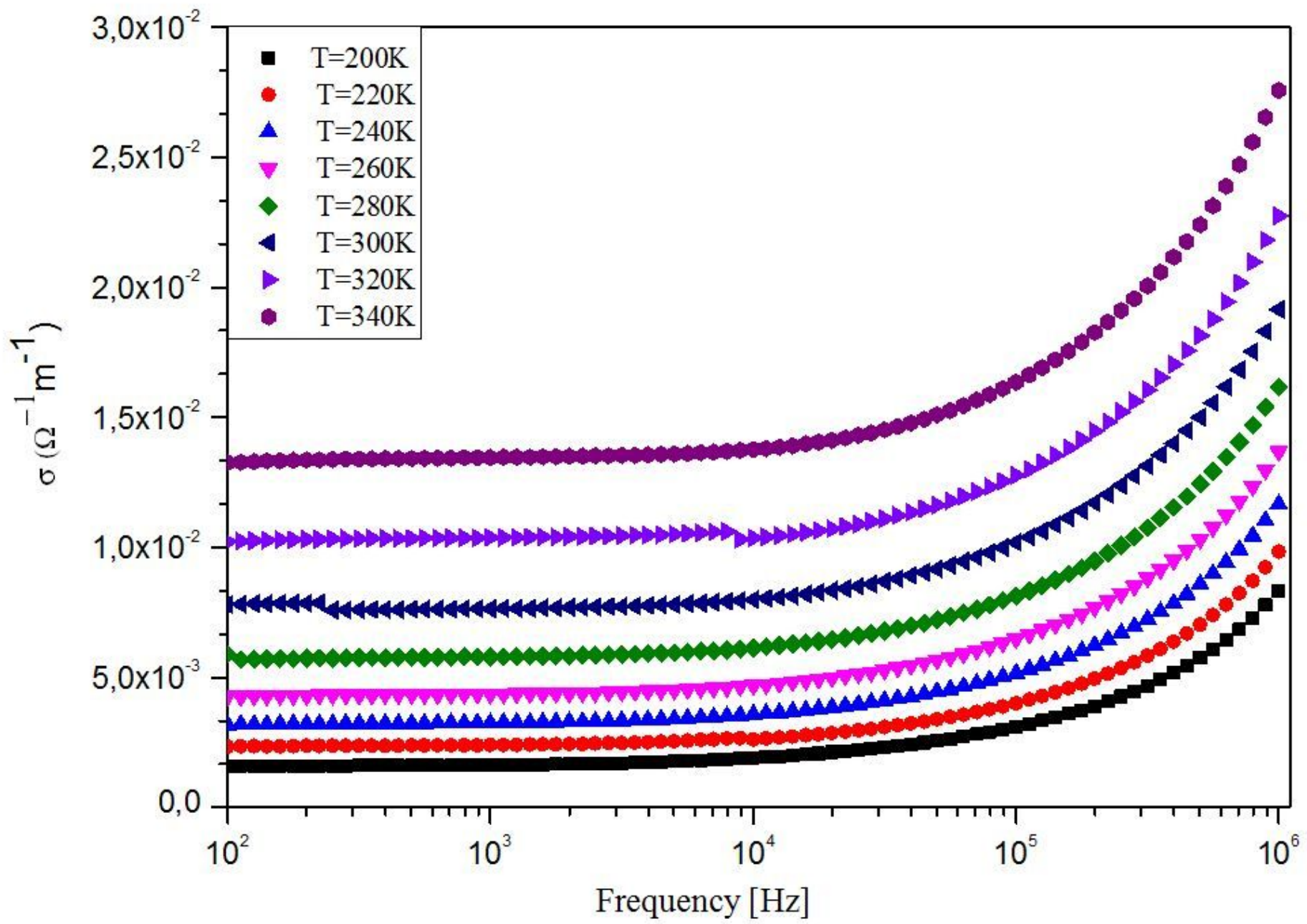

Figure 9

Frequency dependence of the AC conductivity at various temperatures. 


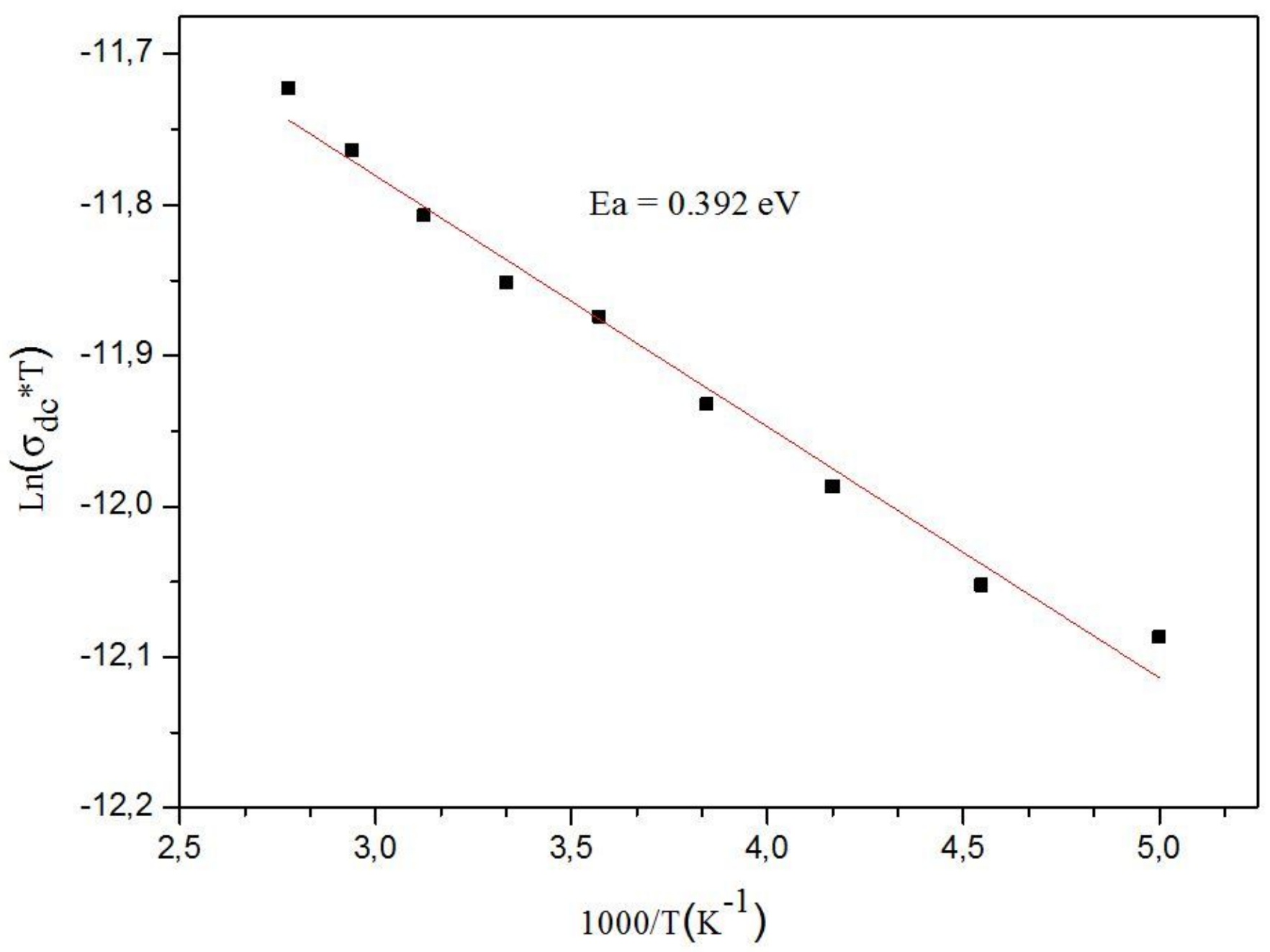

Figure 10

Variation of Ln (бdc xT) as a function of 1000/T. 


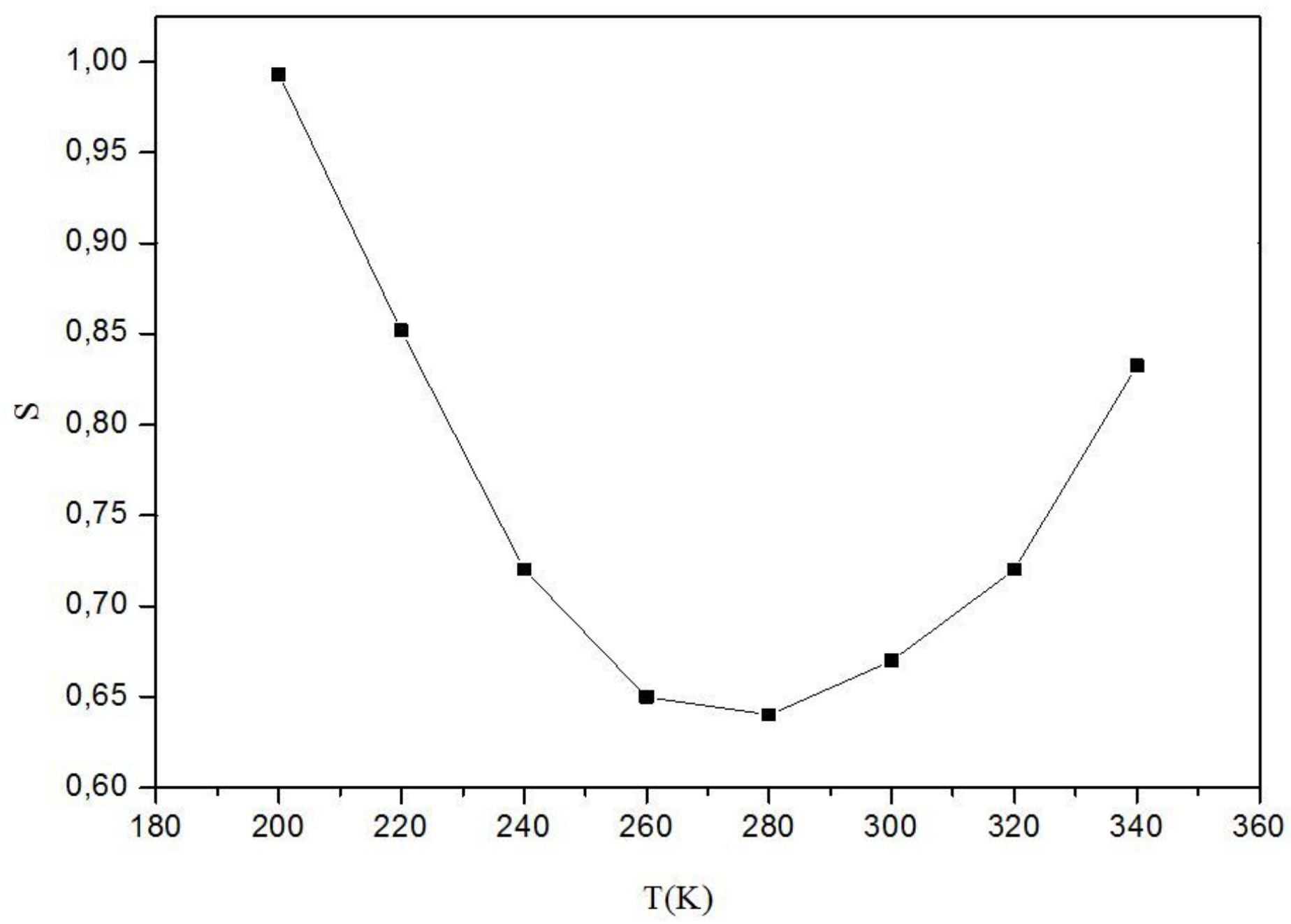

Figure 11

Variation of the universal exponent $\mathrm{S}$ as a function of temperature. 